\title{
TOXICITY OF ORGANOPHOSHOROUS PESTICIDES TO THE MARINE ALGA TETRASELMIS SUECICA
}

\author{
M.C. VAGI $^{1^{*}}$ \\ M.N. KOSTOPOULOU ${ }^{1}$ \\ A.S. PETSAS ${ }^{2}$ \\ M.E. LALOUSI ${ }^{2}$ \\ CH. RASOULI ${ }^{1}$ \\ T.D. LEKKAS ${ }^{2}$
}

Selected from papers presented in $9^{\text {th }}$ International Conference on Environmental Science and Technology (9CEST2005)

1-3 September 2005, Rhodes island, Greece
${ }^{1}$ University of the Aegean, Department of Marine Sciences University Hill, 81100 Mytilini, Greece

${ }^{2}$ University of the Aegean, Dept. of Environmental Studies Water and Air Quality Laboratory University Hill, 81100 Mytilene, Greece

*to whom all correspondence should be addressed Tel: +(30) 2251036824 , Fax: +(30) 2251036809 e-mail: mbag@aegean.gr

\begin{abstract}
Organophoshorous pesticides are widely used in agriculture, because most of them are high effective and low persistent. Yet their increased usage has elicited extensive research into pesticide effects on non-target organisms, such as algae. Algae are of vital importance in the primary production of aquatic ecosystems. Furthermore they have been considered to be indicators of the bioactivity of industrial wastes and they vary in their response to a variety of toxicants.

However little is known about the toxicity of the new pesticides to marine green algae. Laboratory toxicity data concerning responses of aquatic organisms to pesticides are important for focusing on sensitive species exposed to aqueous concentrations of these pesticides in field studies and they also allow prediction of expected responses of aquatic species to a range of pesticides concentrations in situ.

The effects of seven organophosphorous pesticides on the green unicellular marine alga Tetraselmis suecica were studied through $96 \mathrm{~h}$ toxicity tests. The pesticides tested were azinphos ethyl, azinphos methyl, dimethoate, fenthion, parathion ethyl, parathion methyl and disulfoton,. Maximum Specific Population Growth Rates (MSGRs) were calculated for each pesticide tested. Also NOEC, LOEC values and MATC at $96 \mathrm{~h}$ were estimated when compared to the controls.
\end{abstract}

KEYWORDS: organophosphorous pesticides, Tetraselmis suecica, MSGRs, NOEC, LOEC, MATC.

\section{INTRODUCTION}

Pesticides are used till nowadays in agricultural areas due to their potential to control a wide range of insects pests (Ware, 1983). Their application causes serious environmental problems which are multiple and complex, especially those arising from the disposal of identification and the assessment of the toxicity of such substances. Assessment of human exposure to toxicants through biological monitoring offers one means to evaluate the magnitude of the potential health risk of these chemicals (Ma et al., 2001).

Pesticides such as organophosphorous are used widely to control a wide range of pests. However there is a limited published information on their effects on pure cultures of marine algae (Fernandez-Casaderrey et al., 1992; Ma et al., 2001). Considering the algae as being the primary producers in the aquatic environment their importance is crucial in providing energy that sustains invertebrates and fish. The action of toxic 
substances on algae is therefore important not only for the organisms themselves, but also for other links in the food chain.

In a general view, pesticides are a diverse group of widely varying chemical structures, from simple inorganic to complex organic molecules. As soon as they are released in the environment, they can undergo volatilization, adsorption, chemical and/or microbiological transformations (Rand, 1995). Their application for the plants and soil protection can cause adverse effects on aquatic ecosystems in areas nearby agricultural fields. This could be the case of the semi-enclosed gulfs of Kalloni and Geras (Lesvos, Greece), since the organophosphorous pesticides fenthion and dimethoate are widely used to treat olive trees of the watershed area against pests. Those substances can be transferred to the marine environment, leading to the contamination of its flora and fauna. This contamination is most likely to occur during rainfalls or eventually by atmospheric deposition.

It is certain that chemical and physical tests are not sufficient to determine the potentials risks of these toxic substances to the aquatic organisms (Deneer, 2000). In order to evaluate the importance of this aquatic contamination it is necessary to resort to toxicity bioassays. In the present study non target microorganisms, like mikroalga Tetraselmis suecica are used. Modification of growth is used to assess the toxic effects of the chemicals after $96 \mathrm{~h}$ exposure.

\section{MATERIALS AND METHODS}

The green unicellular marine alga Tetraselmis suecica was kindly provided by the National Institute of Marine Fisheries (Kavala, Greece). This species have been routinely cultivated in our laboratory under standardized conditions, such as medium f/2 (APHA, 1998; Nyholm et al., 1989), temperature $20^{\circ} \pm 2^{\circ} \mathrm{C}$ and continuous wide-spectrum light (40W, cool white). All glassware, mediums were previously sterilized. The algal cultures were inoculated in liquid sterilized medium $f / 2$ for 7 days to obtain exponentially growing cultures. Cells in exponential growth phase (about $1^{*} 10^{5}$ cells $\mathrm{ml}^{-1}$ ) were used in the experiments, as they were determined from graphical plots of daily cell counts.

All organophosphorous pesticides (Dr Ehrenstorfer, Germany) were dissolved in acetone (HPLC grade) making up a concentration of the carrier in medium less than $50 \mathrm{\mu l} \mathrm{l}^{-1}$ (Jay, 1996).

The experimental design and test conditions were identical for the 7 selected toxicants tested (azinphos ethyl, azinphos methyl, dimethoate, disulfoton, fenthion, parathion ethyl and parathion methyl). Each experiment included seven treatments: an aged seawater control (C), an aged seawater containing acetone $\left(50 \mu^{\mathrm{I}^{-1}}\right)$, as a carrier for the organic compounds $(C+A)$, and five toxicant exposure concentrations $0.5,1.0,5.0,10.0$ and 15.0 $\mathrm{mg} \mathrm{l}^{-1}$. The five treatment solutions were made by adding appropriate amounts of each toxicant to the $100 \mathrm{~mL}$ of algal nutrient medium. Each treatment contained three replicate flasks. The environmental conditions during the experiments were the same as the growth conditions stated before. Sample flasks were gently shaken during the course of the experiments. Population densities were assessed at four different exposure times (0h), (24h), (72h) and (96h) after the test cultures were inoculated. An improved Neubauer hematocytometer was used to count algal cells. Lugol solution was added to the samples (proportion 1:5) to prevent the natural movement of $T$. suecica cells. The obtained values were plotted against time for the appropriate construction of growth curves.

In each experiment Maximum Specific Population Growth Rates (MSGRs) were calculated for each pesticide tested (Nyholm et al., 1989). Also NOEC and LOEC values at $96 \mathrm{~h}$ were estimated when compared to the controls. MATCs were determined as values representing the geometric mean of the highest no-observed-effect concentration (NOEC) and the lowest-observed-effect concentration (LOEC) (Suter, 1990). 


\section{STATISTICAL ANALYSIS}

Data obtained from the experiments, calculated as percentages and arcsine transformed, were analyzed using one-way analysis of variance (ANOVA). Variances were considered equal $(p>0.05)$ based on Levene's test for homogeneity of variance. The highest concentration of toxicant demonstrating no effect (NOEC) as compared to the controls was estimated by Dunnet's test for statistical significance $(p>0.05)$ with SPSS 12.0 version (2003).

\section{RESULTS - DISCUSSION}

The algal population was not initially affected by exposure to azinphos ethyl and azinphos methyl. Pesticide concentrations of azinphos ethyl above $1.0 \mathrm{mg} \mathrm{I}^{-1}$ significantly reduced $(p<0.05)$ algal densities after $96 \mathrm{~h}$ exposure (Figure 1$)$. The maximum specific growths (MSGRs) of algal populations were significantly reduced by azinphos ethyl at concentrations levels of $5.0,10.0$ and $15.0 \mathrm{mg} \mathrm{I}^{-1}$. Respectively the maximum specific growths of $T$. suecica were significantly reduced $(p<0.05)$ at $15 \mathrm{mg} \mathrm{l}^{-1}$ of azinphos methyl, showing a different sensitivity of the considered algae to this toxicant (Table 1). The algal growth was almost completely inhibited as the concentration of azinphos ethyl increased. An estimation of the no observed effect concentration (NOEC) for azinphos ethyl would be $1.0 \mathrm{mg} \mathrm{l}^{-1}$ and for the lowest observed effect concentration (LOEC) would be and 5.0 $\mathrm{mg} \mathrm{I}^{-1}$. Respectively for azinphos methyl the estimation of NOEC and LOEC would be at $10.0 \mathrm{mg} \mathrm{l}^{-1}$ and $15.0 \mathrm{mg} \mathrm{l}^{-1}$ indicating a different sensitivity of T.suecica to this organophosphorous pesticide.

In the case of dimethoate despite the observed reduction of the MSGR of $T$. suecica when exposed to different concentrations of the toxicant, there was no statistical significance observed $(p<0.05)$ for those values. This can be seen also from the growth inhibition of the algae in Figure 1 . In contrary the growth of the alga was significantly reduced when exposed to concentrations of fenthion, at or greater of $1.0 \mathrm{mg} \mathrm{l}^{-1}$, indicating a greater sensitivity of the algal population to this toxicant. By considering the growth inhibition on $T$. suecica induced by dimethoate and fenthion it can be deduced that the latter affects markedly the algal population than the former (Figure 1). Concentrations of fenthion above $1.0 \mathrm{mg} \mathrm{l}^{-1}$ inhibited completely the growth of the algal population, as it can be seen from the values of the MSGRs (Table 1). An estimate of NOEC and LOEC for fenthion would $0.5 \mathrm{mg} \mathrm{l}^{-1}$ and $1.0 \mathrm{mg} / \mathrm{L}$ respectively.

The MSGRs of algal populations when exposed to low concentrations of parathion ethyl, at 0.5 and $1.0 \mathrm{mg} \mathrm{l}^{-1}$, exhibited no significant inhibition of growth. Concentrations levels of $5.0,10.0$ and $15.0 \mathrm{mg} \mathrm{l}^{-1}$ showed a significant inhibition of $T$. suecica growth $(p<0.05)$. A different sensitivity of the considered alga was observed during the toxicity tests with parathion methyl, which exhibited a significant inhibition of the algal population at $10.0 \mathrm{mg}$ $\mathrm{I}^{-1}$, indicating a different response of the alga to those organophosphorous pesticides. An estimate of NOEC and LOEC would be 1.0 and $5.0 \mathrm{mg} \mathrm{l}^{-1}$ for parathion ethyl and for parathion methyl $5.0 \mathrm{mg} \mathrm{l}^{-1}$ and $10.0 \mathrm{mg} \mathrm{l}^{-1}$ respectively. The latter is in agreement with reported data of similar studies for other species (Ferrando et al., 1991).

The 96h exposure of algal populations of T.suecica to low concentrations of disulfoton did not affect their growth. The MSGRs were significantly reduced $(p<0.05)$ at the levels of $5.0,10.0$ and $15.0 \mathrm{mg} \mathrm{l}^{-1}$ of pesticide concentration with the greatest inhibition observed at the highest concentration. An estimate of the NOEC and LOEC would be 1.0 and 5.0 $\mathrm{mg} \mathrm{l}^{-1}$ respectively. The controls of acetone, which was used as a solvent for the organophosphorous compounds, did not differ significantly ( $p>0.05)$ from blank controls (Table 1).T. suecica exhibited different sensitivity when exposed to the different organophosphorous pesticides cited in this paper. The MSGR NOEC value was larger for azinphos methyl than the corresponding value of NOEC for azinphos ethyl. 
Table 1. Maximum Specific Population Growth Rates (MSGRs) of the Alga T. suecica when exposed to different concentrations of 7 selected Organophosphorous pesticides

\begin{tabular}{|c|c|c|c|c|c|c|c|}
\hline & $\begin{array}{c}\text { azinphos } \\
\text { ethyl }\end{array}$ & $\begin{array}{c}\text { azinphos } \\
\text { methyl }\end{array}$ & dimethoate & fenthion & $\begin{array}{l}\text { parathion } \\
\text { ethyl }\end{array}$ & $\begin{array}{c}\text { parathion } \\
\text { methyl }\end{array}$ & disulfoton \\
\hline$\left(\mathrm{mg} \mathrm{l}^{-1}\right)$ & \multicolumn{7}{|c|}{ Maximum Specific Population Growth Rate $\left(\text { days }^{-1}\right)^{a}$} \\
\hline$C$ & $0.61 \pm 0,02$ & $0.60 \pm 0,02$ & $0.66 \pm 0,02$ & $0.65 \pm 0,06$ & $0.51 \pm 0,03$ & $0.54 \pm 0,02$ & $0.61 \pm 0,03$ \\
\hline$C+A$ & $0.58 \pm 0,04$ & $0,62 \pm 0,05$ & $0.61 \pm 0,04$ & $0.65 \pm 0,03$ & $0.48 \pm 0,04$ & $0.50 \pm 0,04$ & $0.63 \pm 0,01$ \\
\hline 0.5 & $0.55 \pm 0,01$ & $0.66 \pm 0,01$ & $0.57 \pm 0,02$ & $0.58 \pm 0,06$ & $0.52 \pm 0,03$ & $0.44 \pm 0,06$ & $0.58 \pm 0,01$ \\
\hline 1.0 & $0.56 \pm 0,01$ & $0.72 \pm 0,01$ & $0.57 \pm 0,05$ & $0.51 \pm 0,05^{\star}$ & $0.48 \pm 0,04$ & $0.44 \pm 0,01$ & $0.57 \pm 0,02$ \\
\hline 5.0 & $0.06 \pm 0,03^{*}$ & $0.58 \pm 0,01$ & $0.58 \pm 0,04$ & $0.02 \pm 0,07^{*}$ & $0.42 \pm 0,03^{*}$ & $0.45 \pm 0,02$ & $0.40 \pm 0,01^{\star}$ \\
\hline 10.0 & $0.02 \pm 0,01^{*}$ & $0.55 \pm 0,07$ & $0.60 \pm 0,03$ & $0.02 \pm 0,07^{*}$ & $0.02 \pm 0,06^{*}$ & $0.31 \pm 0,02^{*}$ & $0.33 \pm 0,04^{*}$ \\
\hline 15.0 & $0.02 \pm 0,10^{*}$ & $0.19 \pm 0,02^{*}$ & $0.63 \pm 0,05$ & - & $0.02 \pm 0,06^{*}$ & $0.31 \pm 0,01^{*}$ & $0.08 \pm 0,18^{*}$ \\
\hline \multicolumn{8}{|c|}{ Note: Values are means $\pm S D n=3$, except for dimethoate and fenthion where means $\pm S D n=6$} \\
\hline
\end{tabular}

The same trend was observed for parathion methyl, which showed a larger MSGR NOEC value than the corresponding value of parathion ethyl. Fenthion exhibited a greater toxicity to $T$. suecica than dimethoate, with an estimation of the no observed effect concentration being at $0.5 \mathrm{mg} \mathrm{l}^{-1}$. According to this there is a need for further investigation due to its wide use as a pesticide for protection of crops (olive trees, etc). The Maximum Acceptable Toxicity Concentration could be estimated by calculating the geometric mean of the no observed effect concentration (NOEC) and the lowest observed effect concentration (LOEC). According to the obtained results the calculated values of MATC are for azinphos methyl 12,24 $\mathrm{mg} \mathrm{l}^{-1}$, for azinphos ethyl, parathion ethyl and disulfoton $2,23 \mathrm{mg} \mathrm{l}^{-1}$, for fenthion $0,70 \mathrm{mg} \mathrm{l}^{-1}$ and for parathion methyl $7,10 \mathrm{mg} \mathrm{l}^{-1}$.

There is still little information on the sensitivity of marine algae to toxicants, as the most arises from toxicity tests realized on freshwater algae. According to this results freshwater algae exhibit a broad range of sensitivities to toxicants (Walsh et al., 1988). The growth of the algae Nannochloris Oculata was studied when exposed to fenitrothion for 96h (Ferrando et al., 1996), showing a NOEC and LOEC of $1.0 \mathrm{mg} \mathrm{l}^{-1}$ and $5.0 \mathrm{mg} \mathrm{l}^{-1}$ respectively.

\section{CONCLUSIONS}

Nowadays there is a limited information on the toxicity of organophosphorous pesticides to marine algae. The $96 \mathrm{~h}$ growth of the marine alga Tetraselmis suecica was affected differently according to the considered organophosphorous pesticides. Considering that those chemicals are still widely used for the protection of crops and that algae species are less sensitive than other marine species there is a need for further research in this domain. 


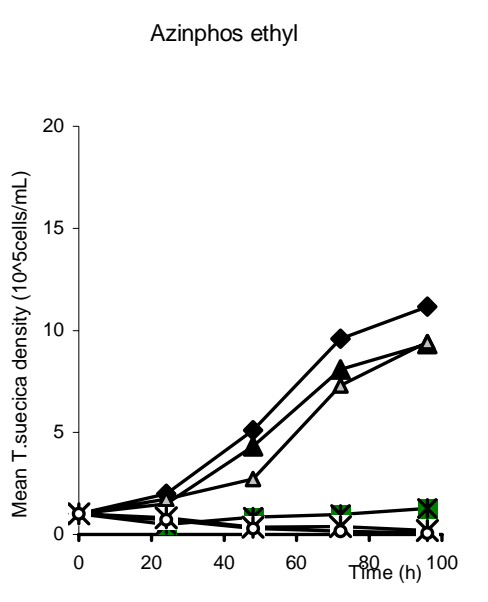

Parathion ethyl

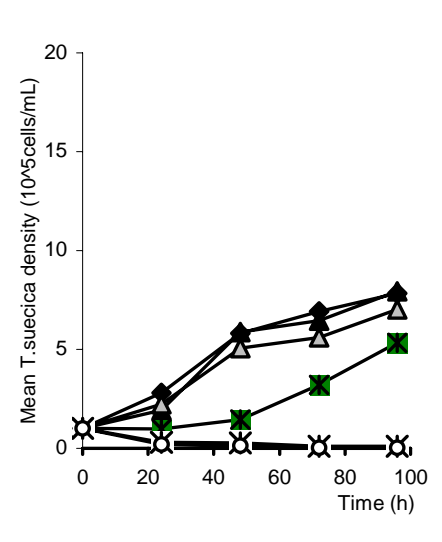

Disulfoton
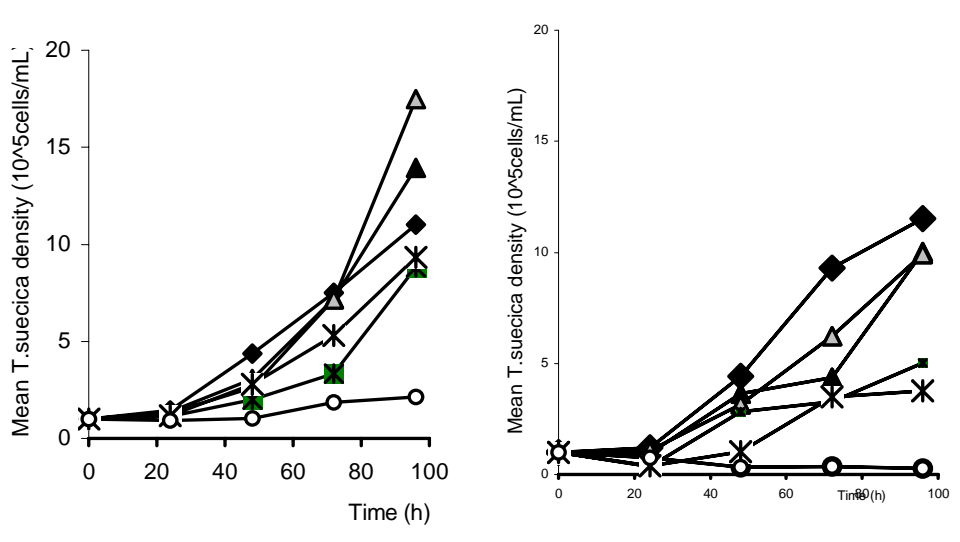

Dimethoate

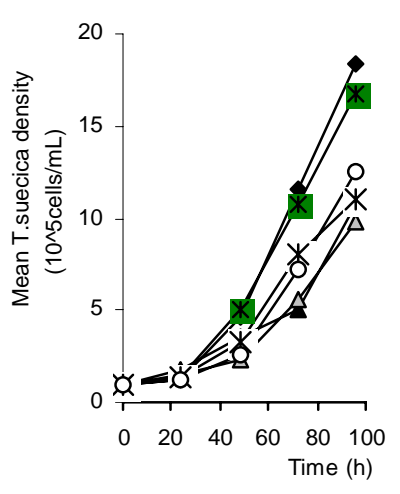

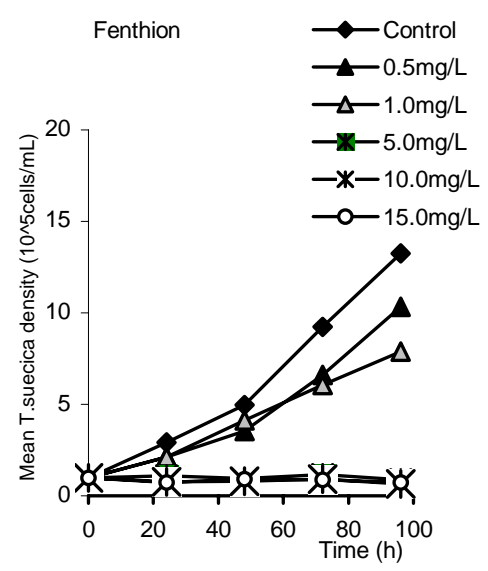

Figure 1. Mean Tetraselmis suecica densities throughout the $96 \mathrm{~h}$ tests conducted with selected organophosphorous pesticides (azinphos ethyl, azinphos methyl, disulfoton, parathion ethyl, parathion methyl, dimethoate and fenthion)

\section{REFERENCES}

APHA (American Public Health Association, American Water Works Association and Water Pollution Control Federation, (1998). Standard Methods for the Examination of Water and Wastewater, $20^{\text {th }}$ edn, American Public Health Association, Washington, DC.

Deneer J.W., (2000). Toxicity of mixtures of pesticides in aquatic systems. Pestic. Manag. Sci. 56, 516-520. 
Ferrando M.D. and Andreu E., (1991) Chronic toxicity of methyl parathion on Dapnia magna: Effects on survival, reproduction and growth. Bull. Environ. Contam. Toxicol. 53(1), 43-49.

Ferrando M.D. Sancho E. and Andreu-Moliner E., (1996) Chronic toxicity of fenitrothion to an algae (Nannochloris oculata), a rotifer (Brachionus calyciflorus) and the cladoceran (Daphnia magna). Ecotox. \& Environ. Safety 35, 112-120.

Fernandez-Casaderrey A., Ferrando M.D. and Andreu-Moliner E. (1992) Acute toxicity of several pesticides to the rotifer Brachionus calyciforus. Bull. Environ. Contam. Toxicol. 48, 14-17.

Jay A.E. (1996) Toxic effect of organic solvents on the growth of Chlorella vulgaris and Selenastrum capricornutum. Bull. Environ. Contam. Toxic. 57,191-198.

Ma J., Liang W. (2001) Acute toxicity of 12 herbicides to the green algae Scenedesmus obliqnus and Chlorella pyrenoidosa to 30 hebicides. Bull. Environ. Contam. Toxicol., 68, 275-281.

Ma J., Liang W. (2001) Acute toxicity of 33 herbicides to the green algae Chlorella pyrenoidosa. Bull. Environ. Contam. Toxicol., 66, 536-541

Nyholm N and Kallqvist, T. (1989) Methods for growth inhibition toxicity tests with freshwater algae. Environ. Toxicol. Chem. 8, 689-703.

Rand G.M. (1995) Fundamentals of Aquatic Toxicology: Effects, Environmental Fate and Risk Assessment, $2^{\text {nd }}$ ed, Taylor and Francis, Philadelphia.

Suter G.W. (1990) Seven-day test and chronic tests. Environ. Toxic. Chem. 9, 1435-1436.

Walsh G.E., Deans C.H., and McLaughlin L.L. (1988) Comparisons of the four methods for calculating the EC50 from algal population growth. Environ. Toxicol. Chem. 6, 767-770.

Ware G.W. (1983) Pesticides. Theory and Application. Freeman, New York. 